\title{
Papel da alfa-sinucleína e da disfunçáo mitocondrial associada à doença de Parkinson
}

\author{
Role of alpha-synuclein and Parkinson's disease-associated mitochondrial dysfunction
}

Rita Perfeito ${ }^{1}$, Ana Cristina Rego ${ }^{2}$

\section{RESUMO}

\begin{abstract}
A doença de Parkinson (DP) é uma doença neurodegenerativa, crônica e progressiva, associada a uma disfunção do movimento. Caracterizase por uma perda selectiva de neurónios dopaminérgicos na substantia nigra e pela presença de corpos de Lewy - agregados maioritariamente compostos pelas proteínas alfa-sinucleína e ubiquitina. Várias hipóteses têm sido propostas para explicar a neurodegenerescência nesta patologia, que envolve factores ambientais (formas esporádicas) e/ou genéticos (formas familiares). A alfa-sinucleína apresenta três mutaçóes que causam a DP na forma autossómica dominante. Para além disso, a duplicação e a triplicação do gene desta proteína estáo igualmente associadas às formas familiares da doença. A disfunção mitocondrial tem também sido ligada à DP. Pretende-se assim neste trabalho de revisão clarificar o papel da alfa-sinucleína e sua relação com a disfunção mitocondrial e a DP.
\end{abstract}

Unitermos. Alfa-Sinucleína, Mitocôndria, Doença de Parkinson.

Citaçáo. Perfeito R, Rego AC. Papel da alfa-sinucleína e da disfunção mitocondrial associada à doença de Parkinson.
Trabalho realizado na Universidade de Coimbra, Coimbra, Portugal. 1. Bióloga, CNC-Centro de Neurociências e Biologia Celular da Universidade de Coimbra, Coimbra, Portugal.

2. Bióloga, Doutora, Professora Auxiliar com Agregação da Faculdade de Medicina e Investigadora do CNC-Centro de Neurociências e Biologia Celular da Universidade de Coimbra, Coimbra, Portugal.

\begin{abstract}
Parkinson's disease (PD) is a chronic, progressive neurodegenerative disorder, associated to impaired movement. It is characterized by a selective loss of dopaminergic neurons from the substantia nigra and by the presence of Lewy bodies - intracytoplasmic inclusions mainly composed by alpha-synuclein and ubiquitin. Multiple hypotheses have been proposed to explain the neurodegeneration in this pathology, that involves environmental factors (sporadic forms) and/ or genetic predisposition (familial forms). Three point mutations in alpha-synuclein gene cause autossomic dominant PD. Furthermore, gene duplication and triplication of alpha-synuclein gene are also associated to familial forms of the disease. Furthermore, mitochondrial dysfunction has long been linked to PD. Taking this in account, herein we clarify the role of alpha-synuclein and its relationship with mitochondrial dysfunction and PD.
\end{abstract}

Keywords. Alpha-Synuclein, Mitochondria, Parkinson Disease.

Citation. Perfeito R, Rego AC. Role of alpha-synuclein and Parkinson's disease-associated mitochondrial dysfunction.

Endereço para correspondência: Prof. Ana Cristina Rego Faculdade de Medicina da Universidade de Coimbra e CNC-Centro de Neurociências e Biologia Celular Rua Larga, Universidade de Coimbra, 3004-504 Coimbra, Portugal. Telefone: +351-239-820190; Fax: +351-239-822776

E-mail: a.cristina.rego@gmail.com

Revisão

Recebido em: 13/10/10

Aceito em: 09/08/11

Conflito de interesses: não 


\section{INTRODUÇÃO}

A acumulação de alfa-sinucleína na forma de agregados filamentosos intracelulares é uma das características patológicas das doenças neurodegenerativas designadas por sinucleinopatias, nas quais se inclui a doença de Parkin$\operatorname{son}^{1}$. Nesta patologia, a proteína alfa-sinucleína na forma fibrilhar é a principal componente dos corpos de Lewy, inclusóes proteicas, intracitoplasmáticas, presentes tanto nas formas esporádicas como familiares desta doença.

A doença de Parkinson (DP) é uma doença neurodegenerativa, progressiva e irreversível associada a um défice da função motora. Formas esporádicas desta doença afectam aproximadamente $2 \%$ da população mundial acima dos 65 anos de idade, havendo uma maior incidência em indivíduos do sexo masculino ${ }^{2}$. Clinicamente, a DP é caracterizada por rigidez muscular, tremor em repouso, bradicinésia (lentidão anormal dos movimentos voluntários), instabilidade postural; alguns pacientes apresentam ainda sintomas relacionados com perturbaçóes psiquiátricas e cognitivas ${ }^{3}$. Em termos patológicos, a DP é descrita através de uma profunda e selectiva perda de neurónios dopaminérgicos localizados numa zona do cérebro denominada por substantia nigra pars compacta, e que projectam para o estriado. Uma outra característica importante desta patologia é a presença dos corpos de Lewy, agregados proteicos compostos maioritariamente por proteínas como a alfa-sinucleína, ubiquitina e sinfilina-1, entre ou$\operatorname{tras}^{4,5}$. A neurodegenerescência selectiva que caracteriza a DP tem sido associada a vários processos intracelulares, nomeadamente a uma disfunção da mitocôndria, a um aumento do stresse oxidativo e da excitotoxicidade, assim como a alterações da conformação das proteínas ${ }^{6}$.

Apesar dos avanços da Medicina e da investigação científica nesta área, a etiologia da DP continua ainda por esclarecer. Esta manifesta-se normalmente na forma esporádica, que se pensa ser devida a uma exposição contínua a toxinas ou factores ambientais, tais como pesticidas, herbicidas, químicos industriais ou metais, ao longo da vida dos pacientes. A idade é também um factor de risco muito evidente, pelo que a DP está associada ao grupo das doenças do envelhecimento. No entanto, e mais recentemente, a DP tem sido também atribuída a uma predisposição genética - formas raras, familiares - devido à identificação de mutaçôes genéticas em determinados genes que codificam para proteínas associadas à doença, e que têm tido um papel significativo no avanço do conhecimento molecular desta patologia neurodegenerativa ${ }^{7,8}$.

O primeiro gene (SNCA) mutado a ser identificado na DP codifica para a proteína pré-sináptica alfa-sinucleína. Três mutaçôes missense que causam a doença na forma autossómica dominante, assim como um aumento da expressão desta proteína a nível celular, têm sido associados à formação de agregados de alfa-sinucleína ${ }^{9}$ e a situações patogénicas. Inclusivamente, foi descrita uma duplicação e triplicação deste gene em cinco famílias independentes ${ }^{10,11}$. Especificamente, a triplicação genômica do gene SNCA é responsável por duplicar a expressão da alfa-sinucleína no tecido cerebral e está maioritariamente associada à forma hereditária que leva ao aparecimento da doença em idades precoces, associada a demência. A duplicação genómica assemelha-se à forma idiopática e parece surgir mais tarde na vida dos pacientes, havendo nestes casos uma maior longevidade ${ }^{12}$.

Em suma, mudanças na conformação da alfa-sinucleína, conducentes à sua agregação e modificações póstraducionais, assim como alterações na função mitocondrial, poderão ser eventos patogénicos chave associados à $\mathrm{DP}^{13,14}$. Como resultado, a elucidaçáo dos mecanismos celulares que influenciam as alteraçóes que ocorrem na bioquímica desta proteína e que levam à sua agregaçáo e consequente disfunçẫo neuronal, necessitam de ser clarificados rapidamente para um melhor conhecimento e percepção desta patologia neurodegenerativa.

Após uma perspectiva inicial sobre os principais aspectos clínicos e neuropatológicos da DP, assim como as principais características da alfa-sinucleína, este artigo de revisão tem como objectivo principal analisar as possíveis funçóes da alfa-sinucleína, a sua relação com a doença de Parkinson e a disfunção mitocondrial, que contribuem para o desenvolvimento desta patologia que afecta a função motora.

\section{MÉTODO}

Para a elaboraçáo do presente trabalho, analisámos diversos estudos que investigaram as principais características neuropatológicas e clínicas da doença de Parkinson, assim como as suas possíveis causas. Para além disso, focámo-nos na recolha de informação específica acerca da 
proteína alfa-sinucleína, que está directamente envolvida no desenvolvimento desta patologia, tanto nos casos esporádicos, como hereditários. Como tal, debruçámo-nos sobre as suas possíveis funçôes, estrutura, mutações genéticas, agregação, modificações pós-traducionais e numa possível relação com a mitocôndria, cujo complexo I se encontra inibido nesta doença.

A pesquisa dos artigos científicos relacionada com o tema desta revisão foi realizada através de busca na base de dados online PubMed, utilizando palavras-chave, tais como (em inglês): Parkinson's disease, alpha-synuclein, oxidative stress, complex I inhibition, mitochondrial dysfunction, aggregation, post-translational modifications, que estabelecessem uma relação entre a doença de Parkinson, a alfa-sinucleína e a disfunção mitocondrial.

\section{RESULTADOS}

Para realizar o presente trabalho foram selecionados 99 artigos publicados em inglês e um em espanhol, dos quais, 12 artigos de revisão e 87 originais. Os artigos selecionados incluíram os artigos iniciais sobre a DP, publicados entre as décadas de 70 e 90 e artigos atuais, publicados entre o período de 2000-2010.

\section{DISCUSSÃO}

\section{ALFA-SINUCLEÍNA-PRINCIPAIS CARACTERÍSTICAS Estrutura e localizaçáo}

A alfa-sinucleína é uma proteína com 140 aminoácidos, com um peso molecular aproximado de $14 \mathrm{kDa}$, que está primariamente presente nos terminais pré-sinápticos, mas que apresenta também uma localização nuclear e, mais recentemente, foi detectada na mitocôndria ${ }^{15,16}$. O gene que codifica para a alfa-sinucleína, designado por SNCA ou PARK1, está localizado no cromossoma 4q21 e consiste em sete exóes, cinco dos quais codificam para a proteína ${ }^{17}$. O splicing alternativo resulta em três variantes: a forma full length da alfa-sinucleína, que codifica para a proteína completa de 140 aminoácidos e que é predominantemente expressa no cérebro, nomeadamente no neocórtex, hipocampo, estriado, tálamo e cerebelo ${ }^{18}$; a variante da alfa-sinucleína com 126 aminoácidos que não possui o exão 3; e a variante da alfa-sinucleína de 112 aminoácidos, que não apresenta o exão $5^{19}$.

A alfa-sinucleína pertence a uma família de prote- ínas de forma nativa "desenrolada" (unfolded) e que náo possui uma estrutura secundária típica. De facto, a alfasinucleína é uma molécula muito dinâmica, cuja estrutura secundária depende do ambiente ao seu redor ${ }^{20,21}$. Em condições patológicas, a alfa-sinucleína desordenada pode sofrer alteraçóes conformacionais, depositar-se e agregar. Tal como referido anteriormente, fibrilhas de alfa-sinucleína são encontradas nos corpos de Lewy, que estáo descritos como uma possível base da neurodegenerescência associada à DP.

Estudos que incidiram na estrutura da alfa-sinucleína revelaram três domínios principais ou regióes: uma regiâo N-terminal (regiāo anfipática: 1-60), uma região central (domínio NAC (do inglês non-Abeta component of Alzheimer's disease) hidrofóbico: 61-95) e a regiāo Cterminal (cauda hidrofílica acídica: 96-140). A região $\mathrm{N}$-terminal é caracterizada por seis sequências repetidas imperfeitas de 11 resíduos (com um motivo KTKEGV) e sabe-se actualmente que forma cinco hélices anfipáti$\operatorname{cas}^{22,23}$. As hélices $1-4$ pensa-se terem a capacidade de se associar a vesículas lipídicas ${ }^{21,24}$, enquanto a hélice 5 parece ser responsável pelas interacçóes proteína-proteí$\mathrm{na}^{20}$. Por outro lado, a região C-terminal, acídica e rica em resíduos de glutamato, permanece desenrolada e não aparenta ter associação com vesículas ou outras molécu$\operatorname{las}^{22}$. Por fim, a região hidrofóbica NAC tem características extremamente amiloidogénicas e, tal como outras proteínas amilóides, esta confere-lhe uma capacidade de alterar a sua estrutura de random coil para folha-beta ${ }^{25}$. Por sua vez, este processo é acompanhado por uma extensa agregação e formação de fibrilhas ${ }^{26}$.

\section{Possíveis funçôes}

Embora a função fisiológica da alfa-sinucleína não seja ainda conhecida, várias linhas de evidência têm sugerido um papel nos terminais nervosos pré-sinápticos, relacionado com processos associados a membranas ${ }^{18,27}$. A estrutura bioquímica da proteína prevê que esta possa funcionar como uma molécula chaperone, com capacidade para se ligar a outras proteínas intracelulares ${ }^{28}$, uma vez que possui homologia com regióes da família das chaperones $14-3-3^{28,29}$. Esta família de proteínas desempenha um papel numa variedade de funçóes celulares, tais como, controlo e regulação da proliferação celular 
em mamíferos ${ }^{30}$, regulação da exocitose e da actividade da proteína cinase $\mathrm{C}^{31}$, estando integrada no grupo das proteínas chaperones citoplasmáticas ubíquas. De acordo com a hipótese das chaperones, também a alfa-sinucleína interage nos terminais sinápticos com numerosas proteínas que regulam a homeostase da dopamina nos neurónios dopaminérgicos nigroestriatais.

A deleção do gene da alfa-sinucleína em ratinhos não interfere com o seu desenvolvimento normal, mas conduz a um aumento da libertação de dopamina nos terminais nigroestriatais, sugerindo que a alfa-sinucleína pode participar como modulador negativo da neurotransmissão da dopamina ${ }^{32}$. Para além disso, a expressão da alfa-sinucleína também altera a captação de dopamina pelo transportador membranar, enfatizando deste modo um papel importante na neurotransmissão da dopamina ${ }^{33}$. A actividade catalítica da tirosina hidroxilase, a principal enzima envolvida na síntese da dopamina, é também regulada pela alfa-sinucleína ${ }^{34,35}$. Esta última parece desempenhar um papel chave na fosforilação da enzima tirosina hidroxilase e, consequentemente, na síntese da dopamina nos neurónios dopaminérgicos ${ }^{34,35}$. A alfa-sinucleína está ainda directamente envolvida no recrutamento da dopamina e na compartimentalização pré-sináptica da mes$\mathrm{ma}^{36}$. Mais ainda, pensa-se que a interacção da alfa-sinucleína com as vesículas sinápticas poderá ser crítica para a sua função normal e influenciar o seu papel patológico na DP. Por fim, foi proposta uma função anti-apoptótica da alfa-sinucleína, através de uma diminuição da função da via da $\mathrm{p} 53^{14,37}$.

\section{Agregação da alfa-sinucleína - influência das muta- çóes pontuais}

Os agregados proteicos consistem em fibras enriquecidas em folhas-beta, que contêm proteínas que sofreram alterações na sua conformação. Vias intracelulares responsáveis pela eliminação destas proteínas alteradas, tais como o sistema ubiquitina proteossoma (SUP) e o processo de autofagia, têm sido relacionados com a formação destas inclusôes ${ }^{38,39}$.

Existem diversos factores que têm sido descritos por acelerar ou facilitar a agregação da alfa-sinucleína e a formação de fibrilhas, nomeadamente: i) Mutaçôes da alfa-sinucleína: A53T e A30P ${ }^{40,41}$; ii) Clivagem (alfa- sinucleína com 120 aminoácidos em vez de 140) ${ }^{42}$; iii) Decréscimo do $\mathrm{pH}$ e aumento da temperatura ${ }^{43,44}$; iv) Interacção com iões metálicos, tais como $\mathrm{Fe}^{2+}, \mathrm{Cu}^{2+}, \mathrm{Al}^{3+}$ e $\mathrm{Co}^{2+}{ }^{45,46}$; v) Interacção com lípidos, 1-metil-4-fenil1,2,3,4-tetrahidropiridina (MPTP), pesticidas (ex. rotenona) e dopamina ${ }^{47}$; vi) Modificações pós-traducionais; vii) Stresse oxidativo, uma vez que o aumento de radicais livres pode quebrar a estrutura em hélice alfa e levar a outras conformaçóes patogénicas ${ }^{48}$; e/ou viii) Falha no SUP $^{49,50}$.

Três mutaçóes pontuais no gene da alfa-sinucleína consideradas patogénicas e localizadas no terminal amínico, estão descritas pela sua associação às formas familiares da DP, nomeadamente as mutações A30P, A53T e E46K. Embora sejam raras, estudos com estas mutaçóes têm contribuído para a elucidação dos mecanismos moleculares relacionados com a acumulação intracelular de alfa-sinucleína. As mutações A30P, A53T e E46K causam a DP na forma hereditária autossómica dominante, representando $5 \%$ de todos os casos desta patologia neurodegenerativa. Em 2004, Zarranz et al. ${ }^{51}$ identificaram a mutação E46K numa família espanhola, igualmente ligada à forma hereditária autossómica dominante da Demência de Corpos de Lewy.

As formas mutantes da alfa-sinucleína formam fibrilhas mais rapidamente do que a proteína wild-type (WT) em solução aquosa ${ }^{52,53}$. Este efeito tem sido atribuído à elevada propensão para agregação dos intermediários parcialmente "enrolados" ${ }^{4}$. Para além disso, estudos in vitro demonstraram que a proteína WT e as formas mutantes A53T e A30P têm a capacidade de se auto-agregarem em fibrilhas, de uma forma dependente do tempo, $\mathrm{pH}$, temperatura e concentração ${ }^{40,55}$.

Embora as mutaçóes A30P e A53T pareçam facilitar a agregação em fibrilhas, outros estudos mostraram que a alfa-sinucleína mutante $\mathrm{A} 53 \mathrm{~T}$ possui taxas de agregação mais elevadas comparativamente à mutação $\mathrm{A} 30 \mathrm{P}$ e à forma WT, talvez devido a uma ruptura da estrutura em hélice alfa da região anfipática do terminal amínico da proteína ${ }^{56}$. Mais ainda, a mutação A53T causa stresse do retículo endoplasmático, contribui para uma disfunção do armazenamento vesicular da dopamina e para a sua acumulação citosólica, promove o stresse oxidativo e alteraçóes disfuncionais do metabolismo ${ }^{57}$ e conduz a 
uma elevada actividade da caspase $3^{58}$. Não obstante, a mutação A30P contribui para uma redistribuição da alfasinucleína para fora do terminal neuronal pré-sináptico através da interrupção da interacção desta proteína com as vesículas sinápticas e domínios lipídicos nas membranas. Um defeito semelhante na ligação às membranas lipídicas foi também associado à mutação $\mathrm{A} 53 \mathrm{~T}^{59}$. Esta dificuldade apresentada pela alfa-sinucleína mutante em se ligar a membranas tem sido considerada um dos passos iniciais que levam à sua agregação e respectiva incorporação em filamentos.

A transfecção de um sistema celular com alfa-sinucleína mutante E46K mostrou um aumento da formação de agregados de alfa-sinucleína, quando comparado com células que expressavam a forma WT ou as formas mutantes $\mathrm{A} 53 \mathrm{~T}$ ou $\mathrm{A} 30 \mathrm{P}^{60}$. Ao contrário do que ocorre com as formas mutantes A53T e A30P, a alfa-sinucleína mutante E46K tem uma capacidade mais elevada de se ligar a lipossomas carregados negativamente ${ }^{61}$, no entanto, forma estruturas amilóides com taxas semelhantes à alfasinucleína mutante A53T e com elevadas taxas quando comparada com a alfa-sinucleína WT ${ }^{53,61}$.

\section{MODIFICAÇÓES PÓS-TRADUCIONAIS}

Mais de 300 modificaçóes pós-traducionais associadas às proteínas, incluindo proteólise, fosforilação, lipidação, oxidação, nitração, glicosilação, acilação e ubiquitinação têm sido frequentemente descritas e são consideradas importantes mecanismos reguladores da estrutura e função das proteínas. Embora estas modificaçóes envolvam uma variedade de processos, todas elas resultam em alteraçóes do tamanho, carga, estrutura e conformação das proteínas, conduzindo a mudanças das características chave, tais como actividade enzimática, afinidade de ligação ou hidrofobicidade proteica ${ }^{62}$.

A estrutura primária da alfa-sinucleína inclui vários locais susceptíveis a modificações pós-traducionais.

\section{Fosforilação da alfa-sinucleína}

A fosforilação de proteínas é a modificação póstraducional mais estudada e provavelmente a mais importante. A alfa-sinucleína pode ser fosforilada in vitro em vários resíduos, incluindo os resíduos de serina 87 e $129^{63,64}$ e três resíduos de tirosina localizados no terminal carboxílico (tirosinas 125, 133 e 136) ${ }^{65}$. De entre estes locais susceptíveis de serem fosforilados, a serina 129 surge extensivamente fosforilada em tecidos cerebrais de pacientes com DP ou outras doenças relacionadas ${ }^{66,67}$, sugerindo um papel da fosforilação deste resíduo na patogénese da doença. Foi mostrado num modelo de Drosophila da doença de Parkinson, que a fosforilação no resíduo de serina 129, aumentava significativamente a toxicidade da alfa-sinucleína in vivo ${ }^{64}$. Estes resultados sugerem que a alfa-sinucleína fosforilada neste resíduo, não sendo já a espécie tóxica, é pelo menos crítica para a formação da entidade proteica tóxica. Outro facto interessante foi descrito por estes autores ao mostrarem que o bloqueio da fosforilação no resíduo de serina 129 estava associado a uma redução da toxicidade e da formação de inclusões. Estudos mais recentes demonstraram que a fosforilação da alfa-sinucleína no resíduo de serina 129 não só contribui para a formação dos corpos de Lewy, como também para a ubiquitinação, outra importante modificação póstraducional $^{68}$.

\section{Ubiquitinação da alfa-sinucleína}

O SUP é um sistema intracelular de degradação de proteínas, responsável pelo "turnover" de proteínas dentro da célula ${ }^{69}$. Neste sistema, as proteínas destinadas a serem degradadas estão covalentemente ligadas com a ubiquitina, uma proteína pequena, de 76 aminoácidos. Este processo ocorre através da formação de uma ligação iso-peptídica entre o grupo amina $\varepsilon$ de um resíduo de lisina do substrato e a glicina 76 localizada no terminal carboxílico da ubiquitina. Esta reacção é complexa, pois requer a acção de enzimas sequenciais: enzima activadora da ubiquitina (E1); enzima conjugadora da ubiquitina (E2) e enzima ligadora da ubiquitina (E3). Normalmente, este processo de ubiquitinação é repetido várias vezes até se formar uma cadeia de poliubiquitinas que se liga ao substrato. A proteína poliubiquitinada é depois endereçada para o proteossoma 265 para ser degradada enzimaticamente. Durante a síntese da cadeia de poliubiquitina, monómeros individuais de ubiquitina são covalentemente ligados uns aos outros por uma outra via de ligação iso-peptídica entre o resíduo de glicina localizado no terminal carboxílico de cada ubiquitina e um resíduo específico de lisina (o mais comum é a lisina 48) do monómero 
anterior de ubiquitina. A molécula de ubiquitina contém um total de sete resíduos de lisina nas posiçóes 6, 11, 27, 29, 33, 48 e $63^{70}$. Embora a cadeia de ubiquitina envolva tipicamente ligaçóes através da lisina 48 que direcciona as proteínas para degradação no proteossoma, a poliubiquitinação pode ocorrer através de outros resíduos de lisina alternativos ${ }^{71}$. A modificação de proteínas pela ubiquitina é um dos principais mecanismos alvo para a degradação das mesmas no proteossoma. Na sua sequência primária de aminoácidos, a alfa-sinucleína contém 15 resíduos de lisina. Embora 4 desses resíduos (21, 23, 32 e 34) tenham sido alvo de estudo de ubiquitinação apenas in vitro, a ubiquitinação da alfa-sinucleína in vivo parece ocorrer nas lisinas 6, 10 e $12^{72}$. Contudo, continua a não estar clarificado se a alfa-sinucleína monomérica necessita de sofrer o processo de ubiquitinação. Devido à forma nativa da alfa-sinucleína, é possível que in vivo, esta não requeira o processo de ubiquitinação. Em vez disso, ela pode entrar directamente para o proteossoma 20S, tal como descrito para outras proteínas pequenas e desenroladas, que podem ser degradadas pelo proteossoma de uma forma independente da ubiquitina ${ }^{73,74}$. No entanto, a presença de alfa-sinucleína ubiquitinada, foi já demonstrada quando ocorre degradação no proteossoma ${ }^{73}$. Mais ainda, está descrito que maioritariamente um, dois e até três motivos de ubiquitina estão conjugados com os corpos de Lewy associados à alfa-sinucleína ${ }^{75}$. Adicionalmente, estudos mostram que espécies de alfa-sinucleína de alto peso molecular, mas não a proteína monomérica, são o substrato para a oligoubiquitinação da alfa-sinucleína em doenças esporádicas de corpos de Lewy ${ }^{75,76}$. Foi também demonstrado que a ubiquitinação através da ligação pela lisina 63 ocorre especificamente em acumulaçóes de alfasinucleína dentro da célula ${ }^{68}$. Tendo em conta todas estas observaçóes, pode sugerir-se que a ubiquitinação da alfasinucleína é um evento patológico directamente associado com a formaçáo de corpos de Lewy ${ }^{75,76}$.

\section{Nitraçáo e oxidaçáo da alfa-sinucleína}

Tanto a nitração como a oxidação estão associadas com a agregação da alfa-sinucleína e têm sido propostas como mecanismos responsáveis pela formação de oligómeros de alfa-sinucleína ${ }^{48,77}$.

Tal como em outras proteínas, a nitração de resí- duos de tirosina da alfa-sinucleína é causada pela formação de espécies reactivas de nitrogénio e, portanto, por stresse nitrosativo. A estrutura primária da alfa-sinucleína contém quatro resíduos de tirosina, localizados nas posiçôes 39, 125, 133 e 136. Em particular, a nitração do resíduo de tirosina 125 resulta numa dimerização da alfasinucleína, enquanto a nitração no resíduo 39, leva a uma redução da ligação às vesículas lipídicas, aumentando as propriedades de polimerização da alfa-sinucleína. Hodara et al. $(2004)^{78}$ revelaram que a alfa-sinucleína solúvel e nitrada não é eficientemente processada por proteases intracelulares, o que pode conduzir à acumulação da mesma e acelerar a formação de fibrilhas. A alfa-sinucleína nitrada no resíduo de tirosina 39, assim como nos resíduos de tirosina 125, 133 e 136 tem sido detectada em corpos de Lewy corticais e neurites distróficas da substantia nigra de cérebros humanos com $\mathrm{DP}^{77}$, assim como em neurónios de hipocampo, apresentando nestes casos uma marcação citoplasmática difusa ${ }^{79}$.

Ao contrário do que foi mencionado anteriormente, Norris et al. $(2003)^{80}$ mostraram que os resíduos de tirosina não são responsáveis pela formação de dímeros covalentemente ligados, nem de oligómeros, após tratamento da alfa-sinucleína com agentes oxidantes puros. Para além disso, a alfa-sinucleína nitrada em um ou mais resíduos de tirosina não tem tendência para formar fibrilhas, enquanto a forma nativa e oxidada desta proteína tem a capacidade de fibrilhogénese nas mesmas condiçóes experimentais ${ }^{80}$.

Tendo em conta o papel do stresse oxidativo na agregação da alfa-sinucleína, foi demonstrado que a exposição a $\mathrm{FeCl}_{2}$ num modelo celular neuronal levava à formação de inclusões de alfa-sinucleína e oligómeros de 34, 54 e $68 \mathrm{kDa}$ e espécies de alto peso molecular ${ }^{81}$. A exposição a $\mathrm{FeCl}_{2}$ também causou um aumento da actividade da CK2. Estes resultados sugerem que mecanismos diferentes, mas inter-relacionados, tais como, o stresse oxidativo e as modificações pós-traducionais da alfa-sinucleína podem contribuir para a agregação da proteína.

Os passos que precedem a formação de fibrilhas da alfa-sinucleína incluem a alteração conformacional de hélice alfa para folha-beta. Para além disso, modificaçóes no stresse nitrosativo e oxidativo podem resultar em ligaçóes covalentes e na estabilização dos filamentos da alfa-sinu- 
cleína, levando à formação de protofibrilhas e fibrilhas ${ }^{14}$. O que é ainda mais interessante é que compostos antioxidantes demonstraram um efeito altamente potente antialfa-sinucleína fibrilhogénica e como desestabilizadores das fibrilhas de alfa-sinucleína, o que está de acordo com o aumento da formação de fibrilhas da alfa-sinucleína em situaçôes de oxidação ${ }^{82}$. Mais ainda, a geração de espécies reactivas de oxigénio e de nitrogénio parece exacerbar os efeitos tóxicos das mutaçóes pontuais da alfa-sinucleína.

\section{DISFUNÇÃO MITOCONDRIAL NA DOENÇA DE PARKINSON - INFLUÊNCIA DA ALFA-SINUCLEÍNA}

A mitocôndria é um organelo celular muito importante na produção de energia na forma de ATP. A disfunção mitocondrial tem sido implicada na patogénese da DP desde há muito tempo. De facto, vários grupos de investigação reportaram uma diminuição da actividade do complexo I da cadeia respiratória mitocondrial na substantia nigra, músculo-esquelético, plaquetas e linfoblastos de pacientes com $\mathrm{DP}^{83-85}$. No entanto, ainda permanece por provar que esta deficiência no complexo I tem uma relaçáo de causa-efeito com a perda selectiva de neurónios dopaminérgicos, característica desta doença.

O complexo I é o maior dos macrocomplexos da cadeia respiratória mitocondrial, e é constituído por 46 subunidades, sete das quais são codificadas pelo $\mathrm{ADN}$ mitocondrial. As restantes 39 subunidades são codificadas por genes nucleares, importadas para dentro da mitocôndria e conjugadas com as restantes subunidades codificadas pelo ADN mitocondrial ${ }^{86-88}$. Assim, a actividade do complexo I pode estar disfuncional devido a defeitos genéticos no $\mathrm{ADN}$ mitocondrial e/ou $\mathrm{ADN}$ nuclear ou ainda por factores que impeçam ou danifiquem a união das subunidades que fazem parte do complexo. Foi inclusivamente reportada a perda de uma subunidade de 8 $\mathrm{kDa}$ do complexo I mitocondrial em cérebros humanos de doentes de Parkinson ${ }^{88}$. Esta disfunção pode levar à auto-oxidação das subunidades catalíticas, conduzindo à disfunçâao do complexo I, e a uma perda da funçâo bioenergética da mitocôndria.

As primeiras evidências de disfunção mitocondrial apareceram após observação de um grupo de toxicodependentes expostos acidentalmente ao MPTP - uma toxina ambiental que resulta num síndroma parkinsónico irreversível ${ }^{5,89}$. O MPTP é um análogo da meperidina (heroína sintética), uma neurotoxina altamente lipofílica. Após a sua admnistração sistémica, o MPTP atravessa rapidamente a barreira hemato-encefálica e entra no cérebro. Uma vez no cérebro, o MPTP é metabolizado em 1-metil-4-fenil-2,3-dihidropiridínio (MPDP+) pela monoamina oxidase B (MAO B), que está localizada na membrana externa da mitocôndria. O MPDP+ é depois espontaneamente oxidado em 1-metil-4-fenilpiridínio $(\mathrm{MPP}+)$, a neurotoxina activa. O MPP+ é internalizado pelos neurónios dopaminérgicos nigroestriatais através dos transportadores da dopamina (para os quais o MPP+ tem uma grande afinidade), localizados nos terminais nervosos do estriado. $\mathrm{O} \mathrm{MPP}+$ também se acumula na mitocôndria através de um mecanismo que envolve o potencial transmembranar mitocondrial, inibindo o complexo I (NADH-quinona oxidoredutase) e, deste modo, interrompendo o transporte de electróes. Este processo tem várias consequências prejudiciais para a célula, nomeadamente: um aumento da produção de espécies reactivas de oxigénio, levando ao stresse oxidativo; um decréscimo da produção de ATP; um aumento intracelular da concentração de cálcio; excitotoxicidade e danos celulares relacionados com o aumento de óxido nítrico ${ }^{5}$. A inibição do complexo I da cadeia mitocondrial também resulta na abertura do poro de transição permeável mitocondrial, havendo a possibilidade de ocorrer libertação de citocromo c, que vai desencadear as vias de sinalização que conduzem à morte celular por apoptose. $\mathrm{O} \mathrm{MPP}+$ decresce igualmente os níveis de dopamina no estriado, levando ao aparecimento dos sintomas característicos da DP ${ }^{90,91}$.

Um outro potente inibidor específico do complexo I - a rotenona (usado anteriormente como um pesticida) - tem sido amplamente estudado, pois é também responsável pela morte celular dopaminérgica ${ }^{92}$. Em estudos anteriores, o grupo de Greenamyre, demonstrou que após a administração deste inibidor selectivo do complexo I a ratos, estes desenvolviam sintomas semelhantes aos da DP, no Homem. Para além disso, a administração de rotenona conduzia à degeneração neuronal e formação de inclusóes ricas em alfa-sinucleína. No entanto, o grau de inibição do complexo I pela rotenona era apenas parcial e insuficiente para danificar a função mitocondrial no cérebro. Para além disso, os efeitos estavam relacionados 
com um aumento da produçáo de radicais livres e um consequente aumento do stresse oxidativo mediado pela mitocôndria ${ }^{93,94}$. Uma vez que os inibidores do complexo I accionam características típicas da DP, o seu uso poderá ser muito útil a nível experimental na compreensão dos mecanismos de morte celular que ocorrem ao longo do desenvolvimento desta doença neurodegenerativa.

Mas estará a inibição do complexo I mitocondrial relacionada com a disfunção da proteína alfa-sinucleína e a DP? Tal como foi referido anteriormente, a alfa-sinucleína encontra-se predominantemente localizada nos terminais sinápticos e no citoplasma dos corpos celulares. Sabe-se actualmente que as alteraçóes desta proteína têm um impacto, ainda que indirecto, mas significativo na função mitocondrial neuronal ${ }^{95,96}$. Para além disso, vários dados suportam a relação muito próxima que existe entre a alfa-sinucleína e os danos oxidativos celulares. Mais ainda, a sobre-expressão de alfa-sinucleína mutante, sensibiliza ainda mais os neurónios para o stresse oxidativo e para os danos causados pela dopamina e toxinas mitocondriais, tais como o MPP+ e a 6-hidroxidopamina (6-OHDA), resultando num aumento da carbonilação de proteínas, peroxidação lipídica in vitro e in vivo ${ }^{95,96}$. A 6-OHDA é uma neurotoxina específica dos neurónios dopaminérgicos in vitro e in vivo ${ }^{97}$. É um composto muito instável, que é facilmente oxidado para produzir espécies reactivas de oxigénio, que poderão causar a morte dos neurónios dopaminérgicos por apoptose. Embora a 6-OHDA seja formada in vitro a partir da dopamina, pensa-se que o mesmo não ocorrerá in vivo. Um factor importante é que a 6-OHDA não atravessa a barreira hemato-encefálica. Como tal, tem sido usada em modelos animais para produzir um denominado hemiparkinsonismo através de injecção estereotáxica directamente na regiāo nigroestriatal ${ }^{91}$.

A expressão de alfa-sinucleína mutante A53T causa alteraçóes bioquímicas numa fase precoce, incluindo uma redução da actividade do proteossoma e um aumento intracelular dos níveis de espécies reactivas de oxigénio em culturas de células diferenciadas num fenótipo neuronal dopaminérgico ${ }^{58}$. Para além disso, tanto o stresse do retículo endoplasmático, como a disfunção mitocondrial têm sido sugeridos por actuarem em conjunto, contribuindo desta forma para a morte celular induzida pela alfa-sinucleína mutante (A53T) através de um decréscimo do potencial membranar mitocondrial, libertação de citocromo c e aumento da actividade das caspases 9 e 3, envolvidas no processo de morte celular por apoptose ${ }^{58}$.

Muito recentemente, um estudo mostrou que em leveduras que expressam altos níveis de alfa-sinucleína (alfa-sinucleina HiTox), a disfunção mitocondrial e o stress oxidativo fazem parte de aspectos significativos da toxicidade da alfa-sinucleína ${ }^{98,99}$. A presença da disfunção mitocondrial foi notável, tendo em conta as evidências já descritas que implicam a actuação das toxinas mitocondriais envolvidas na patogénese da DP. Neste modelo de células de levedura alfa-sinucleina HiTox, as mitocondrias sofreram fragmentação, dilatação e produziram espécies reactivas de oxigénio ${ }^{98,99}$.

\section{CONCLUSÃO}

Os agregados de alfa-sinucleína no cérebro são uma característica molecular das sinucleinopatias, incluindo a doença de Parkinson. Esta doença neurodegenerativa possui uma etiologia multifactorial, que envolve factores genéticos e ambientais. Modificaçôes pós-traducionais da alfa-sinucleína, a proteína que existe em maior quantidade nos corpos de Lewy e a disfunção mitocondrial, parecem estar envolvidas nos mecanismos patogénicos que conduzem a esta doença. A inibição do complexo I mitocondrial leva a uma falha energética na célula e à formação de radicais livres. Para além disso, alteraçôes na alfa-sinucleína podem promover o stresse oxidativo através da regulação da síntese de dopamina, da sua neurotransmissão, e da sua auto-oxidação. No entanto, o stresse oxidativo/nitrosativo, também influenciam a oxidação da alfa-sinucleína e a sua capacidade de agregar. Mais ainda, as mutações genéticas que podem ocorrer no gene desta proteína causam a doença de Parkinson na forma hereditária autossómica dominante. A alfa-sinucleína parece ainda ter influência na função do SUP e da mitocôndria, o que levanta a possibilidade de que as modificações póstraducionais desta proteína (algumas claramente com um papel importante na agregaçáo proteica), possibilitam uma interacção entre vias bioquímicas comuns. Assim, é necessário continuar a estudar e promover a investigação sobre a função da alfa-sinucleína, das suas modificaçóes pós-traducionais e da sua relação com a disfunção mito- 
condrial, no sentido de clarificar a sua relevância na patogénese da doença de Parkinson.

\section{AGRADECIMENTOS}

Agradecemos o financiamento para a realização do trabalho conducente ao grau de Doutor pela Fundação para a Ciência e a Tecnologia (FCT), Portugal, referência SFRH/BD/25515/2005; e ao financiamento do projecto de investigação da FCT, referência PTDC/SAUNEU/101928/2008.

\section{REFERÊNCIAS}

1.Goedert M. Alpha-synuclein and neurodegenerative diseases. Nat Rev Neurosci 2001;2:492-501.

\section{http://dx.doi.org/10.1038/35081564}

2.Rijk MC, Tzourio C, Breteler MMB, Dartigues JF, Amaducci L, Lopez Pousa S, et al. Prevalence of parkinsonism and Parkinson's disease in Europe: the EUROPARKINSON collaborative study. European Community concerted action on the epidemiology of Parkinson's disease. J Neurol Neurosurg Psychiatry 1997;62:10-15.

3.Verbaan D, Marinus J, Visser M, van Rooden SM, Stiggelbout AM, van Hilten JJ. Patient-reported autonomic symptoms in Parkinson disease. Neurology 2007;69:329-330.

http://dx.doi.org/10.1212/01.wnl.0000266593.50534.e8

4.Spillantini MG, Schmidt ML, Lee VM, Trojanowski JQ, Jakes R, Goedert M. Alpha-synuclein in Lewy bodies. Nature 1997;388:839-840.

http://dx.doi.org/10.1038/42166

5.Abou-Sleiman PM, Mugit MM, Wood, NW. Expanding insights of mitochondrial dysfunction in Parkinson's disease. Nat Rev Neurosci 2006;7:207-19. http://dx.doi.org/10.1038/nrn1868

6.Olanow CW, Tatton WG. Etiology and pathogenesis of Parkinson's disease. Annu Rev Neurosci 1999;22:123-44.

http://dx.doi.org/10.1146/annurev.neuro.22.1.123

7.Dawson TM, Dawson VL. Molecular pathways of neurodegeneration in Parkinson's disease. Science 2003;302:819-22.

http://dx.doi.org/10.1126/science.1087753

8.Hardy J, Cookson MR, Singleton A. Genes and parkinsonism. Lancet Neurol 2003;2:221-8.

http://dx.doi.org/10.1016/S1474-4422(03)00350-8

9.Polymeropoulos MH, Lavedan C, Leroy E, Ide SE, Dehejia A, Dutra A, et al. Mutation in the alpha-synuclein gene identified in families with Parkinson's disease. Science 1997;276:2045-7.

http://dx.doi.org/10.1126/science.276.5321.2045

10.Singleton AB, Farrer M, Johnson J, Singleton A, Hague S, Kachergus J, et al. Alpha-synuclein locus triplication causes Parkinson's disease. Science 2003;302:841.

http://dx.doi.org/10.1126/science.1090278

11.Ibanez P, Bonnet AM, Debarges B, Lohmann E, Tison F, Pollak P, et al. Causal relation between alpha-synuclein gene duplication and familial Parkinson's disease. Lancet 2004;364:1169-71.
12.Nishioka K, Hayashi S, Farrer MJ, Singleton AB, Yoshino H, Imai H, et al. Clinical heterogeneity of alpha-synuclein gene duplication in Parkinson's disease. Ann Neurol 2006;59:298-309.

http://dx.doi.org/10.1002/ana.20753

13.Ferrer I. Alpha-synucleinopathies. Neurologia 2001;16:163-70.

14.Beyer K. Alpha-synuclein structure, posttranslational modification and alternative splicing as aggregation enhancers. Acta Neuropathol 2006;112:237-51. http://dx.doi.org/10.1007/s00401-006-0104-6

15.Yu S, Li X, Liu G, Han J, Zhang C, Li Y, et al. Extensive nuclear localization of alpha-synuclein in normal rat brain neurons revealed by a novel monoclonal antibody. Neurosci 2007;145:539-55.

http://dx.doi.org/10.1016/j.neuroscience.2006.12.028

16.Liu G, Zhang C, Yin J, Li X, Cheng F, Li Y, et al. Alpha-Synuclein is differentially expressed in mitochondria from different rat brain regions and dosedependently down-regulates complex I activity. Neurosci Lett 2009;454:187-92. http://dx.doi.org/10.1016/j.neulet.2009.02.056

17.Spillantini MG, Divane A, Goedert M. Assignment of human alpha-synuclein (SNCA) and beta-synuclein (SNCB) genes to chromosomes 4q21 and 5q35. Genomics 1995;27:379-81.

http://dx.doi.org/10.1006/geno.1995.1063

18.Iwai A, Masliah E, Yoshimoto M, Ge N, Flanagan L, de Silva HA, et al. The precursor protein of non-A beta component of Alzheimer's disease amyloid is a presynaptic protein of the central nervous system. Neuron 1995;14:467-75. http://dx.doi.org/10.1016/0896-6273(95)90302-X

19.Xia Y, Saitoh T, Uéda K, Tanaka S, Chen X, Hashimoto M, et al. Characterization of the human alpha-synuclein gene: Genomic structure, transcription start site, promoter region and polymorphisms. JAlzheimers Dis 2001;3:485-94. 20.Davidson WS, Jonas A, Clayton DF, George JM. Stabilization of alpha-synuclein secondary structure upon binding synthetic membranes. J Biol Chem 1998; 273:9443-9.

http://dx.doi.org/10.1074/jbc.273.16.9443

21.Perrin RJ, Woods WS, Clayton DF, George JM. Interaction of human alpha-synuclein and Parkinson's disease variants with phospholipids. Structural analysis using site-directed mutagenesis. J Biol Chem 2000;275:34393-8.

http://dx.doi.org/10.1074/jbc.M004851200

22.Jao CC, Der-Sarkissian A, Chen J, Langen R. Structure of membranebound alpha-synuclein studied by site-directed spin labeling. Proc Natl Acad Sci USA 2004;101:8331-6.

http://dx.doi.org/10.1073/pnas.0400553101

23.Bisaglia M, Schievano E, Caporale A, Peggion E, Mammi S. The 11-mer repeats of human alpha-synuclein in vesicle interactions and lipid composition discrimination: a cooperative role. Biopolymers 2006;84:310-6.

http://dx.doi.org/10.1002/bip.20440

24.Biere AL, Wood SJ, Wypych J, Steavenson S, Jiang Y, Anafi D, et al. Parkinson's disease-associated alpha-synuclein is more fibrillogenic than beta- and gamma-synuclein and cannot cross-seed its homologs. J Biol Chem 2000;275:34574-9.

http://dx.doi.org/10.1074/jbc.M005514200

25.El-Agnaf OMA, Irvine GV. Review: formation and properties of amyloidlike fibrils derived from alpha-synuclein and related proteins. J Struct Biol 2000;130:300-9.

\section{http://dx.doi.org/10.1006/jsbi.2000.4262}

26.Conway KA, Harper JD, Lansbury PT Jr. Fibrils formed in vitro from alpha-synuclein and two mutant forms linked to Parkinson's disease are typical amyloid. Biochemistry 2000;39:2552-63.

http://dx.doi.org/10.1021/bi991447r

27.George JM. The synucleins. Genome Biol 2001;3:1-6.

http://dx.doi.org/10.1186/gb-2001-3-1-reviews3002 
28. Ostrerova N, Petrucelli L, Farrer M, Mehta N, Choi P, Hardy J, et al. Alpha-synuclein shares physiological and functional homology with 14-3-3 proteins. J Neurosci 1999;19:5782-91.

29. Tzivion G, Luo Z, Avruch J. A dimeric 14-3-3 protein is an essential cofactor for Raf kinase acativity. Nature 1998;394(6688):88-92.

http://dx.doi.org/10.1038/27938

30.Rosner M, Hengstschlager M. 14-3-3 proteins are involved in the regulation of mammalian cell proliferation. Amino Acids 2006;30:105-9.

http://dx.doi.org/10.1007/s00726-005-0240-7

31.Jones DH, Martin H, Madrazo J, Robinson KA, Nielsen P, Roseboom $\mathrm{PH}$, et al. Expression and structural analysis of 14-3-3 proteins. J Mol Biol 1995;245:375-84.

http://dx.doi.org/10.1006/jmbi.1994.0031

32.Abeliovich A, Schmitz Y, Farinas I, Choi-Lundberg D, Ho WH, Castillo $\mathrm{PE}$, et al. Mice lacking alpha-synuclein display functional deficits in the nigrostriatal dopamine system. Neuron 2000;25:239-52.

http://dx.doi.org/10.1016/S0896-6273(00)80886-7

33.Sidhu A, Wersinger C, Vernier P. Alpha-synuclein regulation of the dopaminergic transporter: a possible role in the pathogenesis of Parkinson's disease. FEBS Lett. 2004;565:1-5.

http://dx.doi.org/10.1016/j.febslet.2004.03.063

34.Perez RG, Waymire JC, Lin E, Liu JJ, Guo F, Zigmond MJ. A role for alpha-synuclein in the regulation of dopamine biosynthesis. J Neurosci 2002;22:3090-9.

35.Drolet RE, Behrouz B, Lookingland KJ, Goudreau JL. Substrate-mediated enhancement of phosphorylated tyrosine hydroxylase in nigrostriatal dopamine neurons: evidence for a role of alpha-synuclein. J Neurochem 2006;96:950-9. http://dx.doi.org/10.1111/j.1471-4159.2005.03606.x

36. Yavich L, Tanila H, Vepsalainen S, Jakala P. Role of alpha-synuclein in presynaptic dopamine recruitment. J Neurosci 2004;24:11165-70.

http://dx.doi.org/10.1523/JNEUROSCI.2559-04.2004

37.Alves Da Costa C, Paitel E, Vincent B, Checler F. Alpha-synuclein lowers p53-dependent apoptotic response of neuronal cells. Abolishment by 6-hydroxydopamine and implication for Parkinson's disease. J Biol Chem 2002;277:50980-4.

\section{http://dx.doi.org/10.1074/jbc.M207825200}

38.Chung KK, Dawson VL, Dawson TM. The role of the ubiquitin-proteasomal pathway in Parkinson's disease and other neurodegenerative disorders. Trends Neurosci 2001;24(11 Suppl):S7-14.

http://dx.doi.org/10.1016/S0166-2236(00)01998-6

http://dx.doi.org/10.1016/S0166-2236(01)00003-0

39.Ross CA, Poirier MA. Protein aggregation and neurodegenerative disease. Nat Med 2004;10(Suppl):S10-17.

http://dx.doi.org/10.1038/nm1066

40.El-Agnaf OMA, Jakes R, Curran MD, Wallace A. Effects of the mutations Ala30 to Pro and Ala53 to Thr on the physical and morphological properties of alpha-synuclein protein implicated in Parkinson's disease. FEBS Lett 1998;440:67-70.

http://dx.doi.org/10.1016/S0014-5793(98)01419-7

41.Narhi L, Wood SJ, Steavenson S, Jiang Y, Wu GM, AnaW D, et al. Both familial Parkinson's disease mutations accelerate alpha-synuclein aggregation. J Biol Chem 1999;274:9843-6.

http://dx.doi.org/10.1074/jbc.274.14.9843

42.Crowther RA, Jakes R, Spillantini MG, Goedert M. Synthetic filaments assembled from C-terminally truncated alpha-synuclein. FEBS Lett 1998;436:309-12.

http://dx.doi.org/10.1016/S0014-5793(98)01146-6

43.Hashimoto M, Hsu LJ, Sisk A, Xia Y, Takeda A, Sundsmo M, et al. Human recombinant NACP/alpha-synuclein is aggregated and fibrillated in vitro: relevance for Lewy body disease. Brain Res 1998;799:301-6.

http://dx.doi.org/10.1016/S0006-8993(98)00514-9

44.Uversky VN, Li J, Fink AL. Evidence for a partially folded intermediate in alpha-synuclein fibril formation. J Biol Chem 2001;276:10737-44.

http://dx.doi.org/10.1074/jbc.M010907200

45.Paik SR, Shin HJ, Lee JH, Chang CS, Kim J. Copper(II)-induced selfoligomerization of alpha-synuclein. Biochem J 1999;340:821-8.

http://dx.doi.org/10.1042/0264-6021:3400821

46.Paik SR, Shin HJ, Lee JH. Metal-catalyzed oxidation of alpha-synuclein in the presence of Copper(II) and hydrogen peroxide. Arch Biochem Biophys 2000;378:269-77.

http://dx.doi.org/10.1006/abbi.2000.1822

47.Cappai R, Leck SL, Tew DJ, Williamson NA, Smith DP, Galatis D, et al. Dopamine promotes alpha-synuclein aggregation into SDS-resistant soluble oligomers via a distinct folding pathway. FASEB J 2005;19:1377-9.

48.Souza JM, Giasson BI, Chen Q, Lee VM, Ischiropoulos H. Dityrosine cross-linking promotes formation of stable alpha-synuclein polymers. Implications of nitrative and oxidative stress in the pathogenesis of neurodegenerative synucleinopathies. J Biol Chem 2000;275:18344-9.

http://dx.doi.org/10.1074/jbc.M000206200

49.McNaught K, Belizaire R, Isacson O, Jenner P, Olanow CW. Altered proteasomal function in sporadic Parkinson's disease. Exp Neurol 2003; 179:38-46. 50.Recchia A, Debetto P, Negro A, Guidolin D, Skaper SD, Giusti P. Alphasynuclein and Parkinson's disease. FASEB J 2004;18:617-26.

http://dx.doi.org/10.1096/f.03-0338rev

51.Zarranz JJ, Alegre J, Gomez-Esteban JC, Lezcano E, Ros R, Ampuero I, et al. The new mutation, E46K, of alpha-synuclein causes Parkinson and Lewy body dementia. Ann Neurol 2004;55:164-73.

http://dx.doi.org/10.1002/ana.10795

52.Perrin RJ, Woods WS, Clayton DF, George JM. Exposure to long chain polyunsaturated fatty acids triggers rapid multimerization of synucleins. J Biol Chem 2001;276:41958-62.

http://dx.doi.org/10.1074/jbc.M105022200

53.Greenbaum EA, Graves CL, Mishizen-Eberz AJ, Lupoli MA, Lynch DR, Englander SW, et al. The E46K mutation in alpha-synuclein increases amyloid fibril formation. J Biol Chem 2005;280:7800-7.

http://dx.doi.org/10.1074/jbc.M411638200

54.Li J, Uversky VN, Fink AL. Effect of familial Parkinson's disease point mutations $\mathrm{A} 30 \mathrm{P}$ and $\mathrm{A} 53 \mathrm{~T}$ on the structural properties, aggregation, and fibrillation of human alpha-synuclein. Biochemistry 2001;40:11604-13.

http://dx.doi.org/10.1021/bi010616g

55.Amer DAM, Irvine GB, El-Agnaf OMA. Inhibitors of alpha-synuclein oligomerization and toxicity: a future therapeutic strategy for Parkinson's disease and related disorders. Exp Brain Res 2006;173:223-33.

http://dx.doi.org/10.1007/s00221-006-0539-y

56. Conway KA, Harper JD, Lansbury PT. Accelerated in vitro fibril formation by a mutant alpha-synuclein linked to early-onset Parkinson disease. Nat Med 1998;4:1318-20.

http://dx.doi.org/10.1038/3311

57.Lotharius J, Barg S, Wiekop P, Lundberg C, Raymon HK, Brundin P. Effect of mutant alpha-synuclein on dopamine homeostasis in a new human mesencephalic cell line. J Biol Chem 2002;277:38884-94.

http://dx.doi.org/10.1074/jbc.M205518200

58.Smith WW, Jiang H, Pei Z, Tanaka Y, Morita H, Sawa A, et al. Endoplasmic reticulum stress and mitochondrial cell death pathways mediate A53T mutant alpha-synuclein-induced toxicity. Hum Mol Gen 2005;14:3801-11. http://dx.doi.org/10.1093/hmg/ddi396 
59.Fortin DL, Troyer MD, Nakamura K, Kubo S, Anthony MD, Edwards RH. Lipid rafts mediate the synaptic localization of a-synuclein. J. Neurosci 2004;24:6715-23.

\section{http://dx.doi.org/10.1523/JNEUROSCI.1594-04.2004}

60.Pandey N, Schmidt RE, Galvin JE. The alpha-synuclein mutation E46K promotes aggregation in cultured cells. Exp Neurol 2006;197:515-20.

http://dx.doi.org/10.1016/j.expneurol.2005.10.019

61.Choi W, Zibaee S, Jakes R, Serpell LC, Davletov B, Crowther RA, et al. Mutation E46K increases phospholipid binding and assembly into filaments of human alpha-synuclein. FEBS Lett 2004;576:363-8.

http://dx.doi.org/10.1016/j.febslet.2004.09.038

62.Clark RS, Bayir H, Jenkins LW. Posttranslational protein modifications. Crit Care Med 2005;33:S407-S409.

http://dx.doi.org/10.1097/01.CCM.0000191712.96336.51

63.Okochi M, Walter J, Koyama A, Nakajo S, Baba M, Iwatsubo T, et al. Constitutive phosphorylation of the Parkinson's disease associated alpha-synuclein. J Biol Chem 2000;275:390-7.

http://dx.doi.org/10.1074/jbc.275.1.390

64.Chen L, Feany MB. Alpha-synuclein phosphorylation controls neurotoxicity and inclusion formation in a Drosophila model of Parkinson disease. Nat Neurosci 2005;8:657-63.

\section{http://dx.doi.org/10.1038/nn1443}

65.Ellis CE, Schwartzberg PL, Grider TL, Fink DW, Nussbaum RL. Alphasynuclein is phosphorylated by members of the Src family of protein-tyrosine kinases. J Biol Chem 2001;276:3879-84.

http://dx.doi.org/10.1074/jbc.M010316200

66.Fujiwara H. Alpha-synuclein is phosphorylated in synucleinopathy lesions. Nat Cell Biol 2002;4:160-4.

67.Saito Y, Kawashima A, Ruberu NN, Fujiwara H, Koyama S, Sawabe M, et al. Accumulation of phosphorylated alpha-synuclein in aging human brain. J Neuropathol Exp Neurol 2003;62:644-54.

68.Liu C, Fei E, Jia N, Wang H, Tao R, Iwata A, et al. Assembly of Lysine 63-linked ubiquitin conjugates by phosphorylated alpha-synuclein implies Lewy Body biogenesis. J Biol Chem 2007;282:14558-66.

http://dx.doi.org/10.1074/jbc.M700422200

69.Pickart CM. Mechanisms underlying ubiquitination. Annu Rev Biochem 2001;70:503-33.

http://dx.doi.org/10.1146/annurev.biochem.70.1.503

70.Lim KL, Dawson VL, Dawson TM. Parkin-mediated lysine 63-linked polyubiquitination: a link to protein inclusions formation in Parkinson's and other conformational diseases? Neurobiol Aging 2006;27:524-9.

http://dx.doi.org/10.1016/j.neurobiolaging.2005.07.023

71.Pickart CM. Ubiquitin in chains. Trends Biochem Sci 2000;25:544-8.

http://dx.doi.org/10.1016/S0968-0004(00)01681-9

72.Nonaka T, Iwatsubo T, Hasegawa M. Ubiquitination of alpha-synuclein. Biochemistry 2005;44:361-8.

http://dx.doi.org/10.1021/bi0485528

73.Tofaris GK, LayWeld R, Spillantini MG. Alpha-synuclein metabolism and aggregation is linked to ubiquitin-independent degradation by the proteasome. FEBS Lett 2001;509:22-6.

http://dx.doi.org/10.1016/S0014-5793(01)03115-5

74.David DC, LayWeld R, Serpell L, Narain Y, Goedert M, Spillantini MG. Proteasomal degradation of tau protein. J Neurochem 2002;83:176-85.

http://dx.doi.org/10.1046/j.1471-4159.2002.01137.x

75.Tofaris GK, Razzaq A, Ghetti B, Lilley KS, Spillantini MG. Ubiquitination of alpha-synuclein in Lewy bodies is a pathological event not associated with impairment of proteasome function. J Biol Chem 2003;278:44405-11.

http://dx.doi.org/10.1074/jbc.M308041200
76.Hasegawa M, Fujiwara H, Nonaka T, Wakabayashi K, Takahashi H, Lee VM, et al. Phosphorylated alpha-synuclein is ubiquitinated in alpha-synucleinopathy lesions. J Biol Chem 2002;277:49071-6.

http://dx.doi.org/10.1074/jbc.M208046200

77.Giasson BI, Duda JE, Murray IV, Chen Q, Souza JM, Hurtig HI, et al. Oxidative damage linked to neurodegeneration by selective alpha-synuclein nitration in synucleinopathy lesions. Science 2000;290:985-9.

http://dx.doi.org/10.1126/science.290.5493.985

78. Hodara R, Norris EH, Giasson BI, Mishizen-Eberz AJ, Lynch DR, Lee VM, et al. Functional consequences of alpha-synuclein tyrosine nitration: diminished binding to lipid vesicles and increased fibril formation. J Biol Chem 2004;279:47746-53.

http://dx.doi.org/10.1074/jbc.M408906200

79.Gomez-Tortoza E, Gonzalo I, Newell K, Garcia JY, Vonsattel P, Hyman BT. Patterns of protein nitration in dementia with Lewy bodies and striatonigral degeneration. Acta Neuropathol 2002;103:495-500.

http://dx.doi.org/10.1007/s00401-001-0495-3

80.Norris EH, Giasson BI, Ischiropoulos H, Lee VM. Effects of oxidative and nitrative challenges on alpha-synuclein fibrillogenesis involve distinct mechanisms of protein modifications. J Biol Chem 2003;278:27230-40.

http://dx.doi.org/10.1074/jbc.M212436200

81. Takahashi M, Ko LW, Kulathingal J, Jiang P, Sevlever D, Yen SH. Oxidative stress-induced phosphorylation, degradation and aggregation of alphasynuclein are linked to upregaulated CK2 and cathepsin D. Eur J Neurosci 2007;26:863-74.

http://dx.doi.org/10.1111/j.1460-9568.2007.05736.x

82. Ono K, Yamada M. Antioxidant compounds have potent anti-fibrillogenic and fibril-destabilizing effects for alpha-synuclein fibrils in vitro. J Neurochem 2006;97:105-15.

http://dx.doi.org/10.1111/j.1471-4159.2006.03707.x

83.Parker WD Jr; Boyson SJ; Parks JK. Abnormalities of the electron transport chain in idiopathic Parkinson's disease. Ann Neurol 1989;26:719-23.

http://dx.doi.org/10.1002/ana.410260606

84.Schapira AH, Cooper JM, Dexter D, Jenner P, Clark JB, Marsden CD. Mitochondrial complex I deficiency in Parkinson's disease. Lancet 1989;1:1269. http://dx.doi.org/10.1016/S0140-6736(89)92366-0

85. Orth M, Schapira AH. Mitochondrial involvement in Parkinson's disease. Neurochem Int 2002;40:533-41.

http://dx.doi.org/10.1016/S0197-0186(01)00124-3

86.Antonicka H, Ogilvie I, Taivassalo T, Anitori RP, Haller RG, Vissing J, et al. Identification and characterization of a common set of complex I assembly intermediates in mitochondria from patients with complex I deficiency. J Biol Chem 2003;278:43081-8.

http://dx.doi.org/10.1074/jbc.M304998200

87.Ugalde C, Vogel R, Huijbens R, Van Den Heuvel B, Smeitink J, Nijtmans L. Human mitochondrial complex I assembles through the combination of evolutionary conserved modules: a framework to interpret complex I deficiencies. Hum Mol Genet 2004;13:2461-72.

http://dx.doi.org/10.1093/hmg/ddh262

88. Keeney PM, Xie J, Capaldi RA, Bennet Jr JP. Parkinson's disease brain mitochondrial complex I has oxidatively damaged subunits and is functionally impaired and misassembled. J Neurosci 2006;26:5256-64.

http://dx.doi.org/10.1523/JNEUROSCI.0984-06.2006

89.Langston JW, Ballard P, Tetrud JW, Irwin I. Chronic parkinsonism in humans due to a product of meperidine-analog synthesis. Science 1983;219:979-80.

http://dx.doi.org/10.1126/science.6823561

90.Fornai F, Schlueter OM, Lenzi P, Gesi M, Ruffoli R, Ferrucci M, et al. Parkinson like syndrome induced by continuous MPTP infusion: Convergent 
roles of the ubiquitin-proteasome system and alpha-synuclein. Proc Natl Acad Sci USA 2005;102:3413-8.

http://dx.doi.org/10.1073/pnas.0409713102

91.Nagatsu T, Sawada M. Cellular and molecular mechanisms of Parkinson's disease: neurotoxins, causative genes and inflammatory cytokines. Cell and Mol Neurobiol 2006;26:781-802.

http://dx.doi.org/10.1007/s10571-006-9061-9

92.Schapira AHV. Mitochondrial dysfunction in Parkinson's disease. Cell Death Differ 2007;14:1261-6.

http://dx.doi.org/10.1038/sj.cdd.4402160

93.Betarbet, R. Sherer TB, MacKenzie G, Garcia-Osuna M, Panov AV, Greenamyre JT. Chronic systemic pesticide exposure reproduces features of Parkinson's disease. Nature Neurosci 2000;3:1301-6.

http://dx.doi.org/10.1038/81834

94.Marella M, Seo BB, Yagi-Matsuno A, Yagi T. Mechanism of cell death caused by complex I defects in a rat dopaminergic cell line. J Biol Chem 2007;282:24146-56. http://dx.doi.org/10.1074/jbc.M701819200
95.Tabrizi SJ, Orth M, Wilkinson JM, Taanman JW, Warner TT, Cooper JM, et al. Expression of mutant $\alpha$-synuclein causes increased susceptibility to dopamine toxicity. Hum Mol Genet 2000;9:2683-9.

http://dx.doi.org/10.1093/hmg/9.18.2683

96.Orth M, Tabrizi SJ. Models of Parkinson's disease. Mov Disord 2003;18:72937.

http://dx.doi.org/10.1002/mds.10447

97.Kostrzewa RM, Jacobowitz DM. Pharmacological actions of 6-hydroxydopamine. Pharm Rev 1974;26:199-288.

98.Su LJ, Auluck PK, Outeiro TF, Yeger-Lotem E, Kritzer JA, Tardiff DN, et al. Compounds from an unbiased chemical screen reverse both ER-to-Golgi trafficking defects and mitochondrial dysfunction in Parkinson's disease models. Dis.Model Mech 2010;3:194-208.

http://dx.doi.org/10.1242/dmm.004267

99.Auluck PK, Caraveo G, Lindquist S. Alpha-synuclein: membrane interactions and toxicity in Parkinson's disease. Annu Rev Cell Dev Biol 2010;26:211-33.

http://dx.doi.org/10.1146/annurev.cellbio.042308.113313 